\title{
ANÁLISE COMPARATIVA DOS SURTOS E DANOS CAUSADOS PELOS BESOUROS DESFOLHADORES Costalimaita ferruginea (Fabricius, 1801) E Costalimaita lurida (Lefévre, 1891) (Coleoptera: Chrysomelidae) EM PLANTIOS DE EUCALIPTO ${ }^{1}$
}

\author{
Reginaldo Gonçalves Mafia ${ }^{2}$, José Eduardo Petrilli Mendes ${ }^{3}$ e Janaína De Nadai Corassa ${ }^{4}$
}

\begin{abstract}
RESUMO - Os besouros desfolhadores Costalimaita ferruginea (Fabricius, 1801) e Costalimaita lurida (Lefévre, 1891) (Coleoptera: Chrysomelidae) são pragas importantes da cultura do eucalipto. A biologia e comportamento daninho de $C$. ferruginea já foram caracterizados. Todavia, não existem estudos sobre o potencial de $C$. lurida como praga da cultura. Assim, o objetivo deste trabalho foi avaliar, de forma comparativa, os surtos e as injúrias causadas por C. ferruginea e C. lurida em plantios de eucalipto. Para isso, 202,8 mil ha de plantios clonais de eucalipto, nos Estados do Espírito Santo, da Bahia e de Minas Gerais, foram monitorados no período crítico de ocorrência (quente e chuvoso). Os surtos detectados foram caracterizados, determinando-se, por meio de amostragens, a incidência, a severidade e as populações absoluta e relativa do inseto por planta atacada. De forma geral, o comportamento daninho de $C$. lurida foi similar ao de $C$. ferruginea, em termos de época de ocorrência e tipo de injúrias causadas. Todavia, C. lurida apresentou maiores picos populacionais, em termos absolutos (insetos por planta) e relativos (razão entre o número de insetos e altura das plantas atacadas), e atingiu maior proporção de área, podendo ser considerado mais daninho que C. ferruginea. O besouro C. lurida deve ser monitorado considerando os mesmos critérios. Além disso, os surtos desta nova praga poderão ser avaliados quanto ao nível crítico para controle, empregando-se as mesmas premissas adotadas para C. ferruginea. Adicionalmente aos resultados, registrou-se, pela primeira vez, a ocorrência de C. lurida no Estado da Bahia, em plantas de araçá (Psidium guineense, Swartz) (Myrtaceae).
\end{abstract}

Palavras-chave: Pragas florestais; Desfolha por insetos; Surto de pragas.

COMPARATIVE ANALYSIS OF OUTBREAKS AND DAMAGES CAUSED BY LEAF BEETLES Costalimaita ferruginea (Fabricius, 1801) AND Costalimaita lurida (Lefévre, 1891) (Coleoptera: Chrysomelidae) IN EUCALYPT PLANTATIONS

\begin{abstract}
The leaf beetles Costalimaita ferruginea (Fabricius, 1801) and Costalimaita lurida (Lefévre, 1891) (Coleoptera: Chrysomelidae) are important eucalyptus pests. The biology aspects and pest behavior of $\boldsymbol{C}$. ferruginea have already been characterized by previous works, but there are no studies about $\mathbf{C}$. lurida potential to cause damage to eucalyptus yield. This work evaluated and compared the pest outbreaks and injuries caused by $\boldsymbol{C}$. ferruginea and C. lurida to young eucalypt plantations. We have monitored 202.8 thousand hectares of clonal eucalypt plantations in Espírito Santo, Bahia and Minas Gerais states in Brazil during the critical period of pest occurrence (warmest and rainiest seasons). The pest peaks were characterized by the measuring of samples regarding the pest occurrence, the severity of attack and the absolute and relative population of insects per attacked plant. In general, C. Iurida pest behavior was similar to C. ferruginea regarding the period of occurrence and injuries patterns. However, C. lurida has shown heavier infestations
\end{abstract}

\footnotetext{
${ }^{1}$ Recebido em 15.07.2013 aceito para publicação em 04.05.2014.

${ }^{2}$ Fibria Celulose, Centro de Tecnologia, Aracruz, ES, Brasil. E-mail: <rgoncalves@fibria.com.br>.

${ }^{3}$ Universidade Federal de Mato Grosso, MT, Brasil. E-mail: < jose.mendes@fibria.com.br>.

${ }^{4}$ Universidade Federal de Mato Grosso, Brasil. E-mail: <janadenadai@gmail.com>.
} 
considering absolute peaks (insects per plant), relative outbreaks (ratio between number of insects and plant height) and was also distributed in a bigger area, thus causing more damage than C. ferruginea. The beetle C. Iurida should be monitored in the same way and making use of the same criteria and control premises developed to $\boldsymbol{C}$. ferruginea. Additionally to the obtained results, this work recorded for the first time the occurrence of C. Iurida in Bahia State and damages caused by this insect on wild guava plants of Psidium guineense Swartz (Myrtaceae).

Keywords: Forest pests; Insect defoliation; Pest outbreaks.

\section{INTRODUÇÃO}

O setor florestal tem contribuído de forma significativa para a economia brasileira, sendo normalmente impulsionador da geração de renda, empregos, tributos e divisas (VALVERDE et al., 2006; SOARES et al., 2009). Esse desempenho tem melhorado ao longo dos anos, de forma vinculada ao investimento em pesquisa e à inovação tecnológica. O desenvolvimento tecnológico transformou, em pouco mais de quatro décadas, o manejo da cultura do eucalipto em um exemplo de sucesso mundial. Como é do conhecimento da ciência, sem esses avanços ainda estaríamos com os baixos índices produtivos observados na década de 1970, mesmo detendo condições de clima e de solo favoráveis para a cultura do eucalipto.

As pragas que atacam o eucalipto podem causar perdas expressivas em toda a cadeia produtiva, provocando reduções no crescimento e na produtividade ou, mesmo, a morte de mudas nos viveiros e de plantas no campo. Em determinadas situações, os danos causados podem, também, reduzir a qualidade da madeira para determinados fins. No grupo dos besouros desfolhadores, merece destaque o gênero Costalimaita (Coleoptera: Chrysomelidae), que agrupa as espécies Costalimaita ferruginea (Fabricius, 1801) e Costalimaita lurida (Lefévre, 1891), sendo ambas daninhas para a cultura do eucalipto. Todavia, enquanto $C$. ferruginea é apontado como o principal besouro desfolhador da cultura (ANJOS, 1992), praticamente não existem registros e estudos sobre C. lurida (ARNHOLD; GONÇALVES, 2010), principalmente que evidenciem a importância econômica dessa espécie.

$\mathrm{O}$ ataque do besouro-amarelo, C. ferruginea, pode afetar o crescimento, sobrevivência e produtividade dos plantios de eucalipto. Pode atingir árvores em qualquer idade, mas os danos são mais importantes em plantios jovens e em brotações (ANJOS; MAJER, 2003). Em viveiro, o ataque da praga, dependendo da intensidade e da frequência, pode causar a morte de mudas ou, mesmo, inviabilizar o seu aproveitamento para plantio. No campo, surtos intensos da praga em plantios com menos de dois meses de idade, de modo geral, também podem causar a morte das plantas e justificar a realização de operações de replantio.

O besouro-amarelo pode atacar as principais espécies comerciais de eucalipto, pertencentes aos gêneros Eucalyptus e Corymbia. Todavia, os surtos têm sido mais frequentes em híbridos e em espécies puras, como Eucalyptus grandis Hill ex Maiden e E. urophylla S. T. Blake, provavelmente em razão da maior escala de plantio dessas espécies e de seus híbridos. Os surtos da praga são muito comuns nos Estados de Minas Gerais, São Paulo, Espírito Santo, Bahia e Mato Grosso do Sul. O período crítico para a ocorrência da praga coincide com a estação chuvosa, iniciando em setembro e finalizando em março do ano seguinte, nesses Estados. Os maiores picos populacionais da praga ocorrem geralmente entre outubro e dezembro (ANJOS; MAJER, 2003). Além do eucalipto, dentro da família Myrtaceae, o besouro-amarelo causa danos em pitanga (Eugenia uniflora L.), jambolão (Syzygium cumini (L.) Skeels; sinonímia: Eugenia cumini (L.) Druce), goiaba (Psidium guajava L.), araçá (P. guineense, Swartz) e cagaita (Eugenia dysenterica DC) (ANJOS, 1992).

Em plantios de eucalipto, alguns estudos foram realizados objetivando caracterizar os surtos e avaliar o potencial dos danos causados por $C$. ferruginea sobre a produtividade. Todavia, não foram encontrados resultados de estudos sobre o potencial de C. lurida como praga dessa planta. Assim, o objetivo deste trabalho foi analisar, de forma comparativa, os surtos e injúrias causados por C. ferruginea e C. lurida em plantas de eucalipto.

\section{MATERIAL E MÉTODOS}

Os estudos foram realizados em plantios clonais de eucalipto localizados do Centro ao Norte do Espírito Santo (ES), extremo Sul da Bahia (BA) e região Nordeste 
de Minas Gerais (MG), no quadrante compreendido pelas coordenadas $-39^{\circ} 12^{\prime} \mathrm{W}$ e $-17^{\circ} 13^{\prime} \mathrm{S}$ a $-40^{\circ} 48^{\prime}$ W e $-20^{\circ} 7^{\prime} \mathrm{S}$. As áreas de plantio totalizaram $96,5 \mathrm{mil}$ hectares (ES), 98,5 mil hectares (BA) e 7,8 mil hectares (MG), totalizando 202,8 mil hectares. Os plantios de eucalipto foram estabelecidos no espaçamento 3 x $3 \mathrm{~m}$. Os surtos foram registrados em 12 distintos clones de eucalipto, todos híbridos interespecíficos entre E. grandis W. Hill ex Maiden x E. urophylla S.T. Blake.

\subsection{Avaliação dos surtos}

A partir da detecção da ocorrência natural dos besouros desfolhadores, em determinado talhão de plantio ou de condução de rebrota, vistoriou-se a área semanalmente até a realização do controle ou até o completo desaparecimento dos insetos. Em cada área de ocorrência (88 talhões com C. ferruginea e 87 talhões com $C$. lurida), foram instaladas quatro parcelas com 20 plantas em três diferentes pontos de amostragem. Esses pontos foram estabelecidos na borda do talhão, local normalmente mais crítico, em termos de infestação (PC - Borda); em pontos representativos da média de infestação (PM) da área efetivamente afetada (com presença de insetos e de danos); e em pontos representativos da média geral (PMG), quando a infestação ocorreu de forma generalizada, não sendo possível diferenciar áreas críticas. Considerando a combinação talhão e pontos de amostragens, foram instaladas 12 parcelas, sendo avaliadas 240 plantas em cada área de ocorrência.

\subsection{Caracterização dos surtos}

Os talhões atacados foram caracterizados quanto à idade (meses), altura média (m) das plantas, tamanho total da área (ha) e área efetivamente atacada (ha), ou seja, com presença de insetos e de injúrias. A altura das plantas foi determinada com o auxílio de uma trena, e a média dessa variável foi determinada considerando a mensuração, ao acaso, de 100 plantas em cada talhão de plantio ou rebrota afetados. Nas parcelas de avaliação, foram determinadas a incidência (\% de plantas atacadas), a severidade de desfolha (\% de dano por planta atacada) e a população de insetos (n) por planta atacada. A severidade foi estimada com base no estudo desenvolvido por Souza et al. (2008). De posse dos dados de número de insetos por planta atacada e da altura média das plantas, determinou-se a razão entre o número de insetos e a altura das plantas (n.m-1 $)$, a qual foi denominada população relativa (PR), para fins de avaliação do nível crítico dos surtos. Os dados foram anotados para cada talhão, especificando o tipo de manejo (plantio ou condução de rebrota) e a espécie de besouro desfolhador presente em cada local.

\subsection{Análise dos dados dos surtos das pragas e dos danos causados}

Todos os dados foram analisados por talhão atacado pelas pragas, comparando-se as variáveis populacionais e os danos causados por C. ferruginea e C. lurida. Os dados de incidência e severidade, em porcentagem, foram corrigidos para comparação por testes paramétricos. As análises foram realizadas respeitando os pressupostos de homogeneidade e normalidade. Empregou-se o teste t, de Student, a 5\% de probabilidade de erro, para comparação das médias, com o auxílio do software Statistica v.10 (STATSOFT, 2011).

\section{RESULTADOS}

Os surtos de $C$. ferruginea e $C$. lurida foram detectados entre setembro de 2011 a janeiro de 2012. Enquanto o besouro-amarelo C. ferruginea ocorreu nos Estados do Espírito Santo, da Bahia e de Minas Gerais, C. lurida ocorreu em Minas Gerais e na Bahia. Portanto, este é o primeiro registro de $C$. lurida na Bahia.

Em relação ao padrão de ataque dos besouros desfolhadores, foi observado que o comportamento de $C$. lurida é similar ao de $C$. ferruginea, causando injúrias foliares, de forma aleatória no limbo foliar, sem consumo da nervura principal, preferencialmente em folhas e ramos tenros, a partir do ápice da planta. As folhas mais severamente atacadas por $C$. lurida tornaram-se totalmente rendilhadas (alusão do nome popular sugerido) e permaneceram aderidas às plantas, mas secaram após determinado período, geralmente a partir da segunda semana (Figura 1). C. lurida também foi observado, pela primeira vez, causando danos em araçá (Psidium guineense), nas regiões Norte do Espírito Santo (ES) e extremo Sul da Bahia (BA). Entre todas as ocorrências registradas, somente em uma delas besouros dessas duas espécies foram detectados causando danos de forma simultânea.

Ao final do período crítico de ocorrência, foram detectados 88 talhões atacados por $C$. ferruginea e praticamente a mesma quantidade (87 talhões) com ocorrências de $C$. lurida. Todavia, de forma geral, os

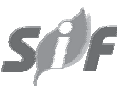

Revista Árvore, Viçosa-MG, v.38, n.5, p.829-836, 2014 


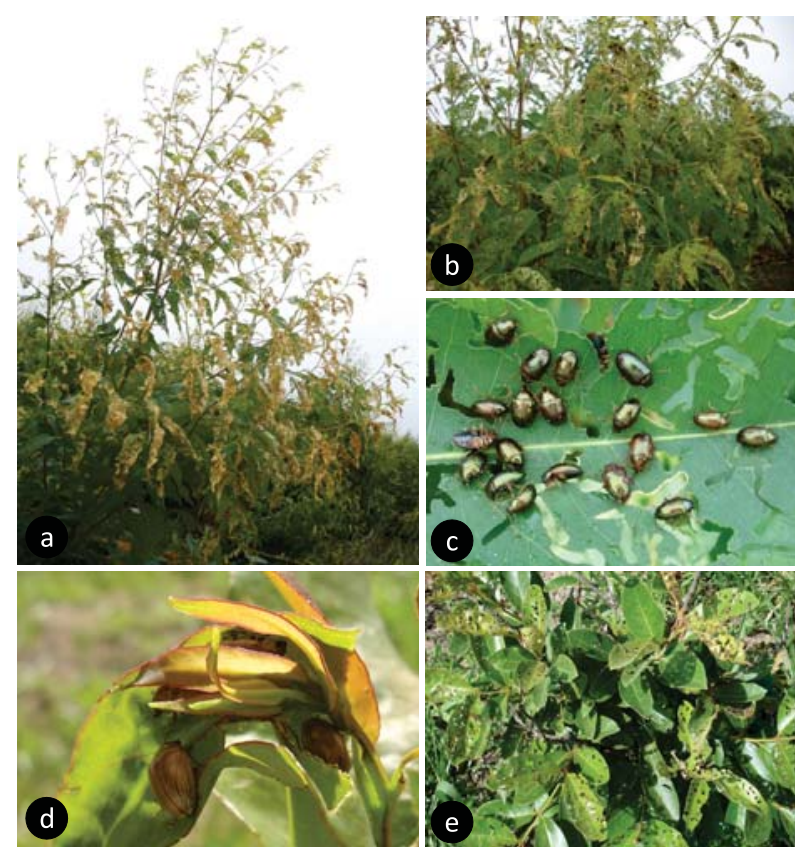

Figura 1 - Injúrias causadas por Costalimaita spp.: a) Danos foliares provocados por C. lurida; b) Ataque na parte apical da copa e presença de grande número de insetos da espécie C. lurida; c) Padrão de injúrias causadas por C. lurida; d) Besouroamarelo (C. ferruginea) protegido em folhas durante o dia; e e) Injúrias foliares causadas por C. lurida em Psidium guineense. Teixeira de Freitas, Bahia. Outubro de 2011.

Figure 1 - Injuries caused by Costalimaita spp.: a) Leaf damage caused by C. Iurida; b) Attack on the upper part of the tree canopy and numerous presence of beetle C. Iurida; c) Injuries patterns caused by C. lurida; d) Yellow beetle $\boldsymbol{C}$. ferruginea protected on leaves during the day; and e) Leaf injuries patterns caused by C. Iurida in Psidium guineense. Teixeira de Freitas, Bahia. October 2011.

surtos de C. lurida afetaram maior proporção de área plantada. Em média, os surtos desta praga atingiram 11,62 ha por área de ocorrência, considerando infestações generalizadas do inseto. Para $C$. ferruginea, o valor foi de 7,97 ha para essa mesma variável. Para as ocorrências localizadas nas bordas dos talhões afetados, observou-se que C. lurida atingiu 48,29 ha, enquanto C. ferruginea causou danos em 7,26 ha. Nos pontos representativos da média de infestação, os valores foram de 1,04 e 32,17 ha para C. lurida e C. ferruginea, respectivamente. Houve diferença também na média geral, e C. ferruginea atingiu 7,88 ha, enquanto C. lurida causou danos em 13,69 ha (Figura 2).
De forma geral, não houve qualquer tipo de tendência de ataque de $C$. ferruginea e C. lurida em relação aos clones de eucalipto, indicando não haver preferência dessas espécies pelos diferentes materiais genéticos de eucalipto plantados na região de estudo. Não houve variação quanto à idade dos plantios afetados, que em média apresentavam cinco meses, com variação de três dias (recém-plantados) até oito meses. As plantas atacadas por ambas as espécies apresentavam entre 1,0 e 1,2 m de altura. Os plantios mais velhos não foram avaliados. Os insetos podem atacar os eucaliptos de qualquer idade, mas são considerados mais prejudiciais durante o primeiro ano da floresta.

O besouro C. lurida apresentou maior dispersão em todas as situações. Essa praga atingiu $100 \%$ de incidência nos pontos críticos, enquanto foram observados apenas $21,4 \%$ de incidência de C. ferruginea nas bordas dos talhões atacados. Na média geral, a incidência do besouro $C$. lurida foi 2,3 vezes maior que a do besouro-amarelo (Figura 2). C. lurida causou maiores danos quando foram consideradas as infestações generalizadas, ou seja, em todo o talhão. Em média, essa praga resultou em $24,8 \%$ de severidade, enquanto o besouro-amarelo danificou $14 \%$ das copas das plantas atacadas. Nos pontos críticos (borda) e em termos médios, não houve diferença entre a severidade dos danos de $C$. ferruginea e C. lurida (Figura 2). Destaca-se que C. lurida apresentou maior população e maior dispersão na área, mas causou o mesmo nível de dano que $C$. ferruginea.

Foram observados maiores picos populacionais do besouro desfolhador C. lurida em todas as situações de avaliação. Em infestações ocorridas de forma generalizada, foram detectados 21,8 indivíduos dessa espécie por planta, enquanto para $C$. ferruginea a média foi de apenas 2,6 indivíduos por planta atacada. Nos pontos críticos, ou seja, na borda dos talhões, a população de $C$. lurida foi cerca de três vezes maior em relação à população do besouro-amarelo. Na média geral, a população de $C$. lurida foi 3,4 vezes maior em relação à população de C. ferruginea (Figura 2).

A razão PR (população relativa) foi maior nos surtos de C. lurida. Para os talhões com infestação generalizada por C. lúrida, a população relativa foi de 20,4 insetos por metro (altura) de planta atacada. Em contrapartida, nessas mesmas situações a população relativa de $C$. ferruginea foi de 3,2 insetos por metro. 

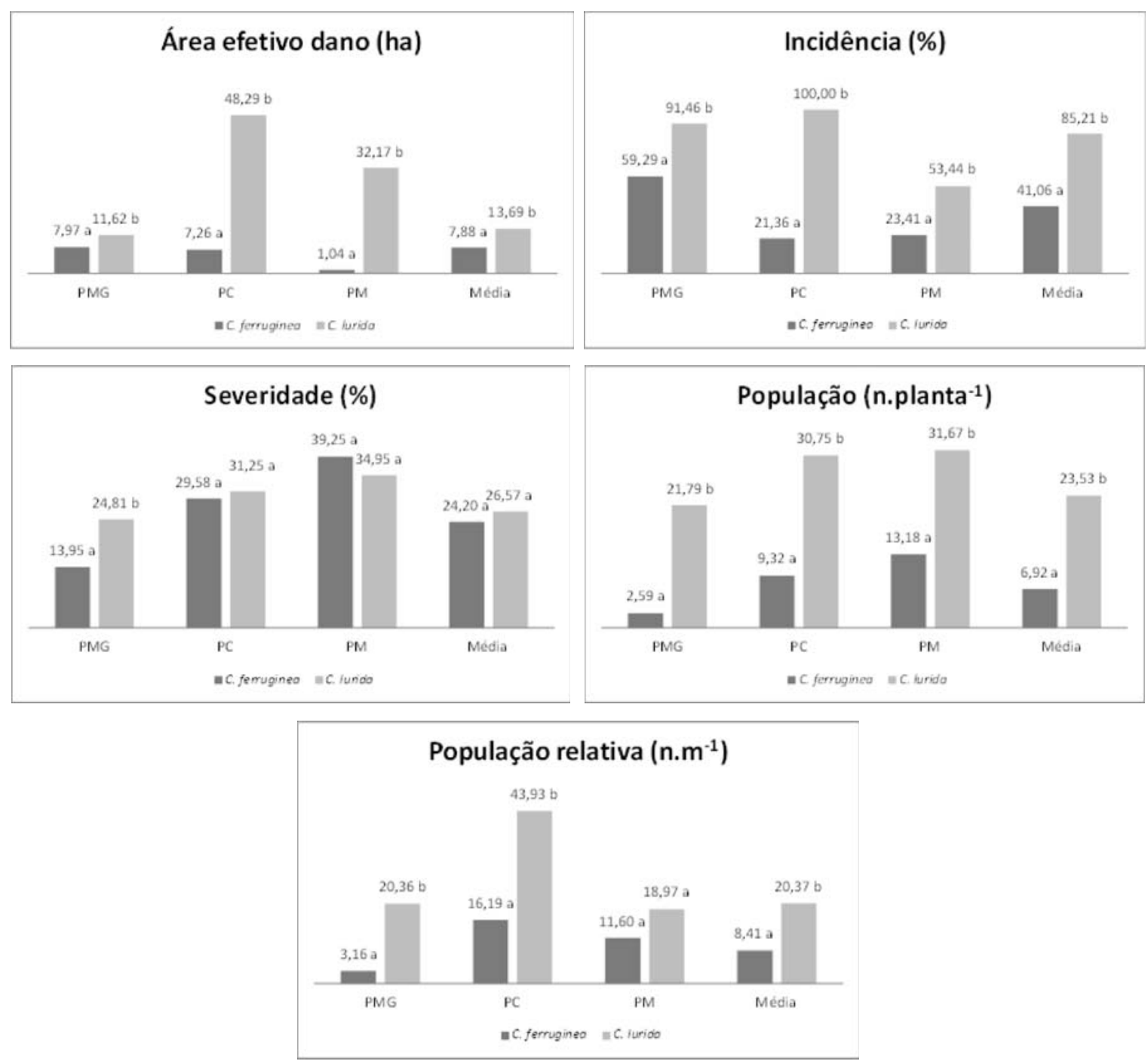

Figura 2 - Área com efetivo dano (ha), incidência (\%), severidade (\%) e população absoluta (n. planta $\left.{ }^{-1}\right)$ e relativa (n.m $\left.{ }^{-1}\right)$ de Costalimaita ferruginea e C. lurida em pontos críticos (PC), representativos da média de infestação (PM) da área efetivamente afetada e em pontos representativos da média geral (PMG).

Figure 2 - Liquid area damaged (ha), incidence (\%), severity (\%) and absolute (t.plant $\left.{ }^{-1}\right)$ and relative population (t. $\left.\mathrm{m}^{-1}\right)$ of Costalimaita ferruginea and C. Iurida at critical points $(P C)$, representative of the infestation (PM) and general average (PMG).

Nos pontos críticos e na média geral, observaram-se valores de 2,7 e 2,4 vezes maiores para C. lurida, em relação ao besouro-amarelo (Figura 2). De forma geral, foram observados valores mais críticos de incidência, nível populacional e de população relativa nos surtos de C. lurida (Figura 3).

\section{DISCUSSÃO}

O comportamento daninho de $C$. lurida foi similar ao de C. ferruginea. Os resultados deste trabalho corroboram as observações de Anjos e Majer (2003), quanto ao período crítico de ocorrência e à forma

Revista Árvore, Viçosa-MG, v.38, n.5, p.829-836, 2014 

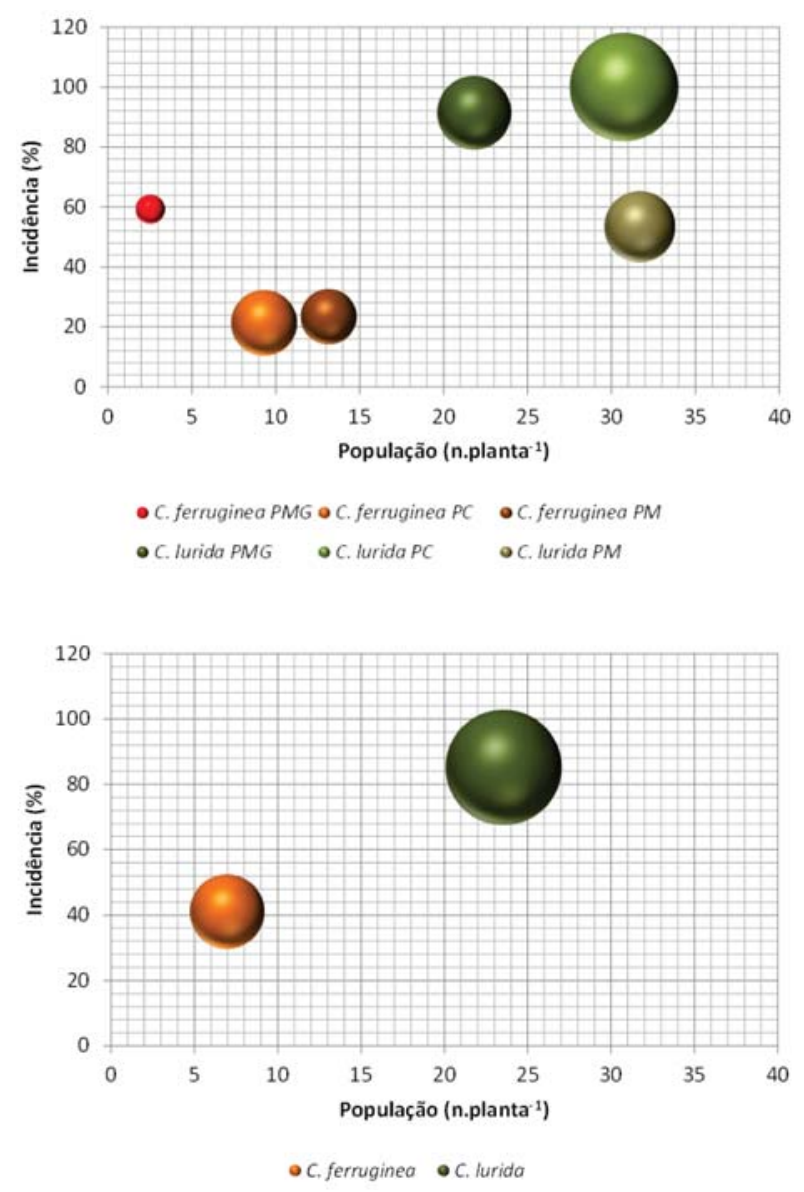

Figura 3 - População relativa (n.m-1) em função da incidência (\%) e da população absoluta (n. planta ${ }^{-1}$ ) de $C$. ferruginea e C. lurida em pontos críticos (PC), representativos da média de infestação (PM) da área efetivamente afetada e em pontos representativos da média geral (PMG).

Figure 3 - Relative population $\left(t^{-m^{-1}}\right)$ according incidence (\%) and absolute (t.plant ${ }^{-1}$ ) population of $\boldsymbol{C}$. ferruginea and C. lurida at critical points (PC), representative of the infestation (PM) and general average (PMG).

como os surtos iniciam e se propagam no campo. Os ataques dos besouros de ambas as espécies ocorreram de forma concentrada, da borda do talhão para o seu interior, normalmente em áreas vizinhas de pastagens. Como se sabe, $C$. ferruginea desenvolve parte do seu ciclo de vida no sistema radicular de gramíneas. Por essa razão, áreas vizinhas de pastagens apresentam maior risco de infestação. Aparentemente, C. lurida tem o mesmo comportamento biológico.
Ambas as espécies de insetos causaram injúrias foliares, preferencialmente a partir do ápice da copa. As injúrias causadas por $C$. ferruginea são caracterizadas, sobretudo, por perfurações foliares realizadas ao acaso. As folhas remanescentes podem ficar completamente rendilhadas, em razão da alta voracidade dessa praga. O besouro-amarelo prefere atacar as partes apicais e tenras do eucalipto, como ponteiros, folhas jovens, brotações e, em alguns casos, a casca dos ramos. Em folhas jovens, pode causar injúrias contínuas e de grande tamanho, enquanto em folhas maduras somente as nervuras principais ficam remanescentes após surtos intensos da praga (ANJOS; MAJER, 2003). A caracterização dos surtos de C. lurida evidenciou o mesmo comportamento daninho.

As respostas de plantas jovens de eucalipto quanto aos danos foliares são variáveis, dependendo da interação dos seguintes fatores: i) a severidade (ou intensidade) e a frequência dos eventos de desfolha dentro e entre os anos de cultivo; ii) a estação do ano quando a desfolha ocorre; iii) a localização dos danos na copa das árvores; e iv) a idade, o vigor e a espécie de eucalipto atacada (COLLETT; NEUMANN, 2002). Dentro de uma mesma espécie, acredita-se, também, que as respostas podem variar, dependo do clone de eucalipto. Em geral, danos foliares severos, especialmente em folhas fotossinteticamente ativas, causam paralisação do crescimento da copa, ramos e raízes, seguidos de morte de ponteiros e, em último caso, mortalidade. Entretanto, injúrias parciais ou de baixa severidade causam, geralmente, reduções pouco significativas no crescimento e, normalmente, ocorre rápida reposição das folhas danificadas (LANDSBERG; OHMART, 1989). Souza et al. (2008), estudando a reposição foliar em plantas jovens de eucalipto após o ataque de $C$. ferruginea, constataram relação inversa entre o nível de desfolha e a capacidade de reposição foliar. Como os danos são variáveis, a recuperação das plantas também não é uniforme. Assim, o ataque do besouro-amarelo causa redução na uniformidade do desenvolvimento do plantio e, consequentemente, no surgimento de plantas suprimidas durante a formação da floresta, o que, segundo Mendes (2004), afeta, de forma significativa, a sobrevivência das árvores em razão do processo de competição entre plantas vizinhas.

Além de causar dano foliar, o que, potencialmente, afeta a taxa fotossintética, os ataques severos de $C$. ferruginea e, ou, de C. lurida podem resultar em danos 
no meristema apical e provocar a perda de dominância apical. A perda de dominância apical está relacionada com alterações do balanço hormonal endógeno. Como reflexo, ocorre quebra da dormência das gemas laterais e emissão de brotações, resultando em redução da capacidade competitiva das árvores atacadas, conforme relatado por Mendes (2004) em relação a plantas de $E$. grandis atacadas por $C$. ferruginea. Collett e Neumann (2002) realizaram um trabalho, no qual duas desfolhas foram simuladas de forma consecutiva, e os efeitos combinados foram avaliados quanto ao crescimento em altura, área basal e incremento volumétrico de um plantio de E. globulus. As desfolhas foram realizadas durante o verão no ápice, base e em toda a copa das plantas. Além de evidenciar redução do crescimento, os autores sugeriram que a poda dos ramos da base da copa pode apresentar efeito benéfico. Em eucalipto, sabe-se que a perda de dominância apical e o surgimento de bifurcações do fuste causam redução no crescimento das árvores. Para contornar esse problema, pode-se realizar a poda corretiva dos ramos laterais, porém é importante ressaltar que essa operação aumenta os custos da formação florestal, podendo ainda causar a abertura de "portas de entrada" para outras adversidades fitossanitárias oportunistas.

Os efeitos do ataque de C. ferruginea em plantios de eucalipto já foram estudados por alguns autores. Anjos (1992), por exemplo, verificou que, um ano após o ataque do besouro-amarelo, em plantio de E. grandis, as reduções médias em diâmetro (DAP) e altura foram, respectivamente, de $14,0 \%$ e $7,7 \%$, sendo o incremento médio anual de árvores atacadas 33\% menor, quando comparado com árvores não atacadas. Mendes (2004) observou que a desfolha causada por essa praga em $75 \%$ da copa resultou na redução de $43,6 \%$ do volume de madeira por hectare, efeitos adversos sobre a forma das árvores e aumento de 1,8 a 3,7 vezes na mortalidade de plantas de E. grandis aos 7 anos de idade. Para C. lurida, apesar de ainda não haver avaliações precisas sobre o efeito no crescimento, acredita-se, com base nos resultados deste trabalho, que os danos sobre as florestas devem ser muito semelhantes ao encontrado em $C$. ferruginea, considerando todas as similaridades quanto ao comportamento daninho dessas duas espécies de pragas.

Apesar dos estudos já desenvolvidos, com base no potencial de danos observados neste trabalho para C. lurida, além daquilo que já foi determinado para C. ferruginea, torna-se fundamental maior investigação sobre o impacto causado por essas espécies na produtividade dos plantios de eucalipto. Para isso, apesar de ser possível simular o efeito por meio de desfolhas artificiais ou determinar diretamente o impacto do ataque de pragas em áreas de ocorrência natural (SMITH et al., 2005), acredita-se que seja mais assertivo modelar o efeito sobre os processos fisiológicos que regulam o crescimento (PINKARD et al., 2011; WHITEHEAD et al., 2011). Os modelos são ajustados para simular e predizer a produtividade florestal para aplicação em plantios uniformes de uma única espécie, e originalmente esses modelos baseados em processos foram desenvolvidos sem considerar o efeito dos danos causados por pragas. Entre os modelos, os mais apropriados para integrar esses efeitos no ecossistema florestal são os modelos CABALA (BATTAGLIA et al., 2011) e CenW (KIRSCHBAUM et al., 2007), e os processos mais críticos para avaliação incluem os efeitos das desfolhas sobre a absorção líquida de carbono, fenologia foliar, balanço de carbono, ciclagem de nutrientes e disponibilidade de água (PINKARD et al., 2011; KURZ et al., 2008).

Neste trabalho, os surtos de populações de $C$. ferruginea e C. lurida foram monitorados por meio de parcelas de medições, instaladas ao acaso na borda dos talhões e em pontos representativos da média de infestação. Esse tipo de avaliação é importante para determinação mais acurada do nível de infestação e para mapeamento das áreas mais críticas dentro de um mesmo talhão de plantio. A borda dos talhões geralmente é o ponto crítico, onde se concentram os danos de maior intensidade. Normalmente, as revoadas dessas espécies de besouros ocorrem a partir de regiões vizinhas aos plantios, notadamente com pastagens ou cultivos de cana-de-açúcar (ANJOS; MAJER, 2003). A partir das bordas dos plantios, em um segundo momento os insetos se dispersam ao longo do talhão, podendo causar danos de forma generalizada, de acordo com o tamanho da população da praga e a idade do plantio.

As plantas atacadas foram avaliadas quanto à intensidade de desfolha, e determinaram-se as populações geral e específica dos insetos. De forma geral, C. lurida apresentou maiores picos populacionais. É importante estabelecer, para cada uma das pragas, o nível crítico de infestação, principalmente considerando a população relativa. Essa variável considera a altura da planta atacada, fornecendo informação simples e confiável para avaliação do nível crítico de infestação.

Revista Árvore, Viçosa-MG, v.38, n.5, p.829-836, 2014 


\section{CONCLUSÃO}

Conclui-se que o comportamento daninho de $C$. lurida foi similar ao padrão comportamental de $C$. ferruginea, em termos de época de ocorrência, tipo de injúrias e, consequentemente, de danos causados aos plantios de eucalipto. Todavia, C. lurida apresentou maiores picos populacionais, em termos absolutos e relativos, atingindo maior proporção de área atacada.

Em razão da importância de C. lurida e diante dos poucos trabalhos sobre essa espécie, sugere-se o nome besouro-rendeiro para denotar popularmente esta nova praga da cultura do eucalipto.

\section{REFERÊNCIAS}

ANJOS, N. Taxonomia, ciclo de vida e dinâmica populacional de Costalimaita ferruginea (Fabr., 1801) (Coleoptera: Chrysomelidae), praga de Eucalyptus spp. (Myrtaceae). 1992. 165f. Tese (Doutorado em Entomologia) - Escola Superior de Agricultura “Luiz de Queiroz”, Piracicaba, 1992.

ANJOS, N.; MAJER, J. D. Leaf-eating Beetles in Brazilian eucalypt plantations. Curtin: School of Environmental Biology, 2003. 33p. (Bulletin 23)

ARNHOLD, A.; GONÇALVES, D. Ocorrência de Costalimaita lurida (Coleoptera: Chrysomelidae) em Eucalyptus spp. em Minas Gerais. Pesquisa Florestal Brasileira, v.30, n.63, p.257-259, 2010.

BATTAGLIA, M. et al. Modelling the impact of defoliation and leaf damage on forest plantation function and production. Ecological Modelling, v.222, n.17, p.3193-3202, 2011.

COLLETT, N. G.; NEUMANN, F. G. Effects of simulated chronic defoliation in summer on growth and survival of blue gum (Eucalyptus globulus Labill.) within young plantations in northern Victoria. Australian Forestry, v.65, n.2, p.99-106, 2002.

KIRSCHBAUM, M. U. F. et al. Modelling net ecosystem carbon and water exchange of a temperature Eucalyptus delegatensis forest using multiple constraints. Agricultural and Forest Meteorology, v.145, n.1, p.48-68, 2007.
KURZ, W. A. et al. Mountain pine beetle and forest carbon feedback to climate change. Nature, v.452, p.987-990, 2008.

LANDSBERG, J.; OHMART, C. Levels of insect defoliation in forests: patterns and concepts. Trends in Research, Ecology and Evolution, v.4, n.1, p.96-100, 1989.

MENDES, J. P. E. Efeito do ataque do Costalimaita ferruginea (Fabr.)

(Coleoptera: Chrysomelidae) sobre o crescimento e produção de Eucalyptus grandis W. Hill ex Maiden. 2004. 49f. Tese (Doutorado em Entomologia) - Universidade Federal de Viçosa, Viçosa, MG, 2004.

PINKARD, E. A. et al. Estimating forest net primary production under changing climate: adding pests into the equation. Tree Physiology, v.31, p.686-699, 2011.

SMITH, A. H. et al. Precision and accuracy of pest and pathogen damage assessment in young Eucalypt plantations. Environmental Monitoring and Assessment, v.111, p.243256, 2005.

SOARES, N. S. et al. Análise do mercado brasileiro de celulose, 1969-2005. Revista Árvore, v.33, n.3, p.563-573, 2009.

SOUZA, R. M. et al. Capacidade de reposição foliar em eucaliptos atacados por Costalimaita ferruginea (Fabricius). In: CONGRESSO FLORESTAL ESTADUAL, 10., SEMINÁRIO MERCOSUL DA CADEIA MADEIREIRA, 1., 2008, Nova Prata. Anais... Nova Prata: 2008.

STATSOFT, Inc. STATISTICA (data analysis software system), version 10 . www.statsoft.com. 2011.

VALVERDE, S. R.; SOARES, N. S.; SILVA, M. L. Desempenho das exportações brasileiras de celulose. Revista Árvore, v.30, n.6, p.10171023, 2006.

WHITEHEAD, D. Modelling the impacts of pests on forest productivity: a pathway through complexities and conundrums. Tree Physiology, v.31, p.683-685, 2011. 